\title{
Knowledge citizenship - an opportunity for post retirement
}

\author{
Melanie Sutton \\ Knowledge Officer \\ The IQ Business Group \\ msutton@iqgroup.net
}

\section{Introduction}

Embracing knowledge citizenship as an alternative to the normal post-retirement lifestyle is an exciting opportunity for the number of retiring baby boomers whose biological age belies their chronological age. Their ability to influence society positively and their power to become exemplary role models for the future generation make them prime candidates for knowledge citizenship.

While a knowledge citizenship profile includes having capabilities of civic responsibility, tolerance, solidarity and self-motivation, two discerning features of knowledge citizenship that are of particular interest to both retirees and businesses that are experiencing a dearth of skills as baby boomers retire, include a culture of knowledge sharing and a commitment to participating in life-long learning opportunities.

\section{Post retirement profile}

Usually people retire for one of two major reasons, namely they have reached the mandatory retirement age or they have poor health.

Many retirees are healthy and can expect to live at least 20 years after retirement; they have the freedom to enter a new phase of their lives that offer opportunities for new societal roles, new community involvement and changes in personal lifestyles. Many want to continue to participate in life-long learning activities and to enjoy new leisure pastimes and hobbies. They are self-reliant and do not want to become burdens to their families or society.

While some new retirees feel a deep loss of personal value, self-esteem becomes an issue as patterns of living change and the possibility of inactivity and boredom arises. Morale can drop year by year and is most markedly observed between the ages of 64 and 69 or in the five-year period after retirement. Literally, the day one retires, the person is cut off from the past and must adapt to a new status (De Beauvoir 1970). Although previous work can be viewed as a time-consuming and restrictive necessity that dominates one's life, it is also a source of stability, focused interest, and an established role within society. In 1680, SaintEvremond wrote: 'Nothing is more usual than old people yearning for retirement; and nothing is so rare than those who have retired and do not regret it' (De Beauvoir 1970, cited in Reapass 1999).

It is important that retirees have a plan for life post retirement and it is important that they 
have choices for the plan. Knowledge citizenship provides opportunity and choices which give value and purpose to post-retirement lifestyles, but is dependent on two important activities, namely a culture of sharing one's knowledge and a participation in life-long learning.

\subsection{Culture of knowledge sharing}

Knowledge, that is 'know-how' that people carry in their minds and which is therefore difficult to access, is a valuable commodity in today's economy. Often, people are not aware of the knowledge they possess or how it can be valuable to others. Tacit knowledge is considered more valuable because it provides context for people, places, ideas and experiences. The effective sharing of tacit knowledge generally requires extensive personal contact and trust and often consists of habits and culture that we do not recognize in ourselves.

\subsection{Importance of life-long learning}

Life-long learning is the concept of continuous personal development through personal (selfactualized) learning. The process involves changing one's perceptions and practice to meet the rapidly changing demands of the knowledge society, by moving away from learning as preparation for life and work, to learning as an integral part of life and work.

Life-long learning is crucial for citizens to be able to compete in the global economy, but it is important for other reasons as well. By improving a person's ability to function as a member of his or her community, education and training increase social cohesion, reduce crime and improve income distribution. Life-long learning impacts learners' lives and changes their mindsets. New technologies also offer new possibilities for people to learn in their lifespan.

Life-long learning assists people in adapting to their roles in society and the world in which they live. An individual can continue throughout life to gain fulfilment and achieve a better quality of life - socially, mentally, physically and educationally.

\section{Knowledge citizenship in action}

The baby-boom generation is a demographic term for the population born between 1946 and 1964. Organizations are concerned about the impending dearth of knowledge and experience as baby boomers prepare for retirement. Retiring boomers' knowledge is complex and deep and their contacts and experience cannot be transferred in a few conversations, seminars and presentations and the loss of talent and knowledge poses a threat to an organization's competitiveness.

However, knowledge citizenship, characterized by a culture of knowledge sharing and a willingness to participate in life-long learning may hold the key to this impending challenge. In fact, knowledge citizenship is prevalent in many big businesses today.

Many companies are making efforts to accommodate the older employees. Some older or retired employees are asked to remain as consultants or to assume training positions. Others may be rehired, hired on a part-time basis, or designated as a non-regular staff member. Even though their wages and benefits decrease, many retirees find this to be a role they enjoy. At times, companies may assist employees by establishing private businesses, developing training programmes for new employees with older employees or retirees serving as lecturers, or contracting with outplacement companies to assist in finding them other employment (Suzuki 1996, quoted in Reapass 1999).

Organizations may consider allowing retired workers access to their intranets and including them in their expert locator programmes. Organizations may also include retirees in 
communities of practice or wisdom transfer programmes, where an older employee who possesses endangered skills is paired with a younger worker.

Deloitte and Touche Inc., a global business consulting firm, has instituted its senior partners programme to retain senior executives who wanted less travel, shorter hours and more flexibility. The firm asked them to write their own job descriptions.

Georgia Pacific, one of the world's largest manufacturers and distributors of building materials, has offered retention incentives to their older research PhDs (Dennis 2006). Procter and Gamble and Eli Lilly worried that the exit of boomers would decimate their research and development departments and have invented Yourencore.com, an online network of retired and semi-retired research scientists and engineers. These companies match available brain talent to short-term research and development projects with a database of 470 scientists. Bank of America helped spawn Senior4Hire.org, a Web site where companies seeking mature workers can post available jobs.

\section{Conclusion}

Adopting a knowledge citizenship attitude of knowledge sharing and life-long learning offers retirees an opportunity to continue to actively engage in society and it may lead to a better quality of life, personal fulfilment, productive community involvement and better mental and physical health. Organizations will also benefit from the transfer of knowledge, skills and experience.

\section{References}

Dennis, H. 2006. Retirement - it's the new competition for US employers. [Online]. Available WWW http://www.asaging.org/publications/dbase/AT/AT-272-Dennis.pdf.

Lonergan, B. Managing the retirement brain drain: a case-study from the manuscripts branch at the National Library of Australia. [Online]. Available WWW http://www.nla.gov.au/nla/staffpaper/2007/documents/BLongergan-brain-drain.pdf.

Reapass, M.E. 1999. Change: retirement in Japan and the resulting challenges for Japanese adult education. [Online]. Available WWW http://scholar.lib.vt.edu/theses/available/etd080299-145701/unrestricted/Repass.pdf.

\section{About the author}

Melanie Sutton (BA, Postgraduate Diploma in Information Management) is a Senior Principal Consultant in the Enterprise Content Management Discipline and a member of Intellectual Property Forum at The IQ Business Group, South Africa.

\section{Disclaimer}

Articles published in SAJIM are the opinions of the authors and do not necessarily reflect the opinion of the Editor, Board, Publisher, Webmaster or the Rand Afrikaans University. The user hereby waives any claim he/she/they may have or acquire against the publisher, its suppliers, licensees and sub licensees and indemnifies all said persons from any claims, lawsuits, proceedings, costs, special, incidental, consequential or indirect damages, including damages for loss of profits, loss of business or downtime arising out of or relating to the user's use of the Website. 
Published by InterWord Communications for Department of Information and Knowledge Management, University of Johannesburg 